\title{
3
}

\section{Environmental Sustainability in Ports}

Eduardo Lalla-Ruiz ${ }^{1,2}$, Leonard Heilig ${ }^{2}$, Stefan $V o \beta^{2}$

${ }^{1}$ Department of Industrial Engineering and Business Information Systems, University of Twente, Enschede, The Netherlands; ${ }^{2}$ Institute of Information Systems, University of Hamburg, Hamburg, Germany

\section{O U T L I N E}

1. Introduction

2. The Concept and Areas of Environmental Sustainability in Ports 68

3. A Brief Overview of Maritime Logistics and Port Operations 74

4. An Application to Berth Scheduling 78

4.1 Description of the Problem 78

4.2 Including Environmental Sustainability in Berthing Operations 79

4.3 Improving Sustainability in the Berth Allocation Problem 83

5. Conclusions 85

References $\quad 86$

\section{INTRODUCTION}

The transportation of freight in containers is one of the main engines of the global economy since it allows reducing transportation costs as well as enabling rapid intermodal operations between different transportation 
modes. In this context, environmental aspects around transportation are increasingly taken into consideration as more containers over larger distances are being handled. The United Nations Conference on Trade and Development (UNCTAD, 2016) underpins this trend in its yearly Review of Maritime Transport, where developments in seaborne trade and the performance assessment of different geographic regions and countries around the world are reported. Due to the preparation of sustainable development goals considered in the UNCTAD Environment Program, the reports started to put a special focus on the interrelationship between maritime transport and sustainable development, as reported in recent reports since 2015.

With the aim of providing a proper context to environmental sustainability, we first set some of the main definitions concerning sustainable development. One of the widestly used ones is given by the Brundtland Commission which defines sustainability as "the development that meets the needs of the present without compromising the ability of future generations to meet their own need" (Brundtland, 1987). Mihyeon Jeon and Amekudzi (2005) show that, when it comes to transportation systems, definitions share a common consensus that transportation systems must generally consider economic development, environment, and social wellbeing.

Environmental sustainability specifically refers to principles and practices supporting this development by ensuring eco-friendly production and selection of resources on the one hand, and efficient use of resources, disposal of waste, and reduction of greenhouse gas (GHG) emissions, on the other hand, to avoid (i.e., mitigate) a negative impact on future generations. Thus, environmentally sustainable ports should manage resources without compromising the current and future natural resources and mechanisms involved in the environmental preservation. In this regard, Antão et al. (2016) indicate that the expansion of ports and their operations can have an adverse environmental impact due to the implications of port planning and operations for the air, water, soil, noise, and sediment of maritime and terrestrial quality. This way, ports must face a double goal. That is, besides progressing in their given economic goals such as aiming to increase their competitiveness and productivity, they need to take particular care of the impacts the decisions and development have on the environmental future of the surrounding area and-in a wider context-on the planet. This requires an adaption of logistics operations in an intelligent way by means of frameworks and tools enabling and supporting the management, control, and monitoring of environmental impacts along the time for all the operational levels. In this respect, Lam and Van de Voorde (2012) indicate that air pollution is one of the major environmental impacts of maritime ports. 
For meeting the aforementioned goals, over the last few years public institutions, shipping companies, as well as terminal and port managers, have been working on the development and application of different strategies to include the environmental sustainability dimension in their agenda. The European Sea Ports Organization (ESPO) in its green guide (ESPO, 2012) provides and encourages guidelines to integrate environmental objectives into daily port operations and management practices. It highlights the transport and logistics chain as an important level to intervene. Similarly, the American Association of Port Authorities (AAPA) in its Environmental Management Handbook (AAPA, 1998) point out that the environmental impact reduces substantially when appropriate environmental management techniques are implemented. Furthermore, the last port environmental review presented by EcoPorts (ESPO, 2016) reported that $92 \%$ of the 91 European ports participating in their program have implemented an environmental policy and $82 \%$ of them monitor their environmental impact. Many of them have issued port development plans and strategies that postulate the implementation of means to reduce the environmental impact on surrounding neighborhoods (see, e.g., Hamburg Port Authority, NSW Ports, Port of Rotterdam Authority). The reduction of emissions and noise is one of the main priorities at many ports, especially in those affected by urbanizing regions surrounding the ports, referred to as port cities.

This chapter first puts the concept of environmental sustainability in maritime ports into perspective by using a framework that classifies major fields of interest from a practical and scientific point of view. The framework provides a comprehensive overview of distinct types of approaches for addressing environmental sustainability at different operational levels. To introduce green aspects into specific planning and optimization problems, we give an overview of container terminal operations and specifically focus on berth scheduling tasks within container terminals. To a considerable extent, the impact of slow steaming and vessel arrivals allows reducing the overall emissions, while in some cases it also allows lowering economical costs. Therefore, we present and discuss examples of decision support approaches for berth planning considering environmental indicators.

The remainder of this chapter first introduces the concept of environmental sustainability and a classification scheme concerning core areas for addressing environmental sustainability in maritime ports. To put the focus specifically on container terminal operations, we further describe the main functional areas and related planning problems. By means of an exemplary problem in port operations, we show how the different environmental sustainability concepts and strategies (e.g., slow steaming) can be included in decision support approaches from a planning and optimization angle. Finally, some conclusions are presented. 


\section{THE CONCEPT AND AREAS OF ENVIRONMENTAL SUSTAINABILITY IN PORTS}

Due to the problems of climate change as well as the increasing requirements for the logistics and transportation industry, environmental sustainability has become one of the key cornerstones on the agenda of many maritime ports. The environmental impacts of ports are quite significant, especially due to the various sources and forms of port-related emissions, such as those from seagoing vessels, heavy-duty trucks, and cargo-handling equipment (Geerlings and Vellinga, 2018). Apart from that, the port community consists of various actors and stakeholders with different perspectives and interests in terms of environmental sustainability. Recently, several impacts on port sustainability in general have been discussed in the literature. A bibliometric analysis and literature review on green ports is presented in Davarzani et al. (2016). The study reveals focal areas of research based on a keyword analysis and citation clusters. Sislian et al. (2016) present a literature review on the interplay between port sustainability and network optimization for ocean carriers. Denktas-Sakar and Karatas-Cetin (2012) propose a framework to study the influence of supply chain stakeholders on port sustainability based on resource dependence theory. While those overviews and categorizations especially focus on the main sources of sustainable issues in ports, in the first part of this chapter, we aim to provide a framework for addressing the governance perspective. By this means, an overview of fundamental governance areas with respect to environmental sustainability in ports as well as a link to best practices and innovative approaches is provided.

As the term environmental sustainability describes a broad concept, it is important to first identify key areas in the context of maritime ports. Based on previous research, we identify six core research areas that have gained attention in industry and academia. In Fig. 3.1, we present a framework to put those core areas into perspective and further refer to related overviews. First, environmental objectives, pursuing a green strategy, as well as performance indicators, measuring the success of management efforts, need to be defined. The green strategy takes stakeholder interests, public policies and regulations, and social responsibility into account. Given this foundation, various practices and instruments exist to achieve environmental objectives. In the proposed framework, we differentiate between policies and regulations, environmental performance indicators, management practices, infrastructure and technologies, and planning and optimization. Continuous improvement can be obtained by auditing, measuring, and monitoring the progress as a feedback function on the one hand, and by facilitating an alignment between the strategy, projects, operations, and technology. Thereby, new technological developments and advancements in the port infrastructure, for instance, may create new 


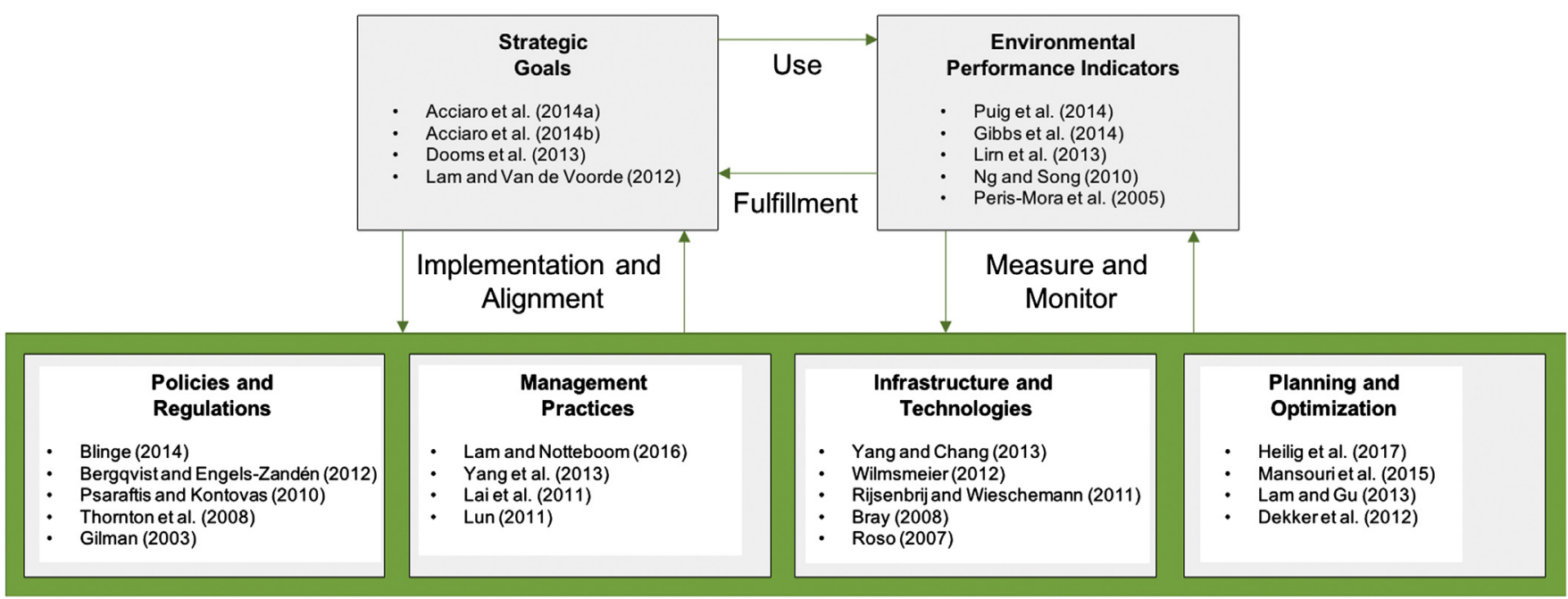

FIGURE 3.1 Major areas of environmental sustainability in ports. 
opportunities for adapting port strategies, business models, and operations - as we currently see with respect to smart port initiatives.

In the following, we briefly describe the core areas in order to give a short overview of potential fields of action in maritime ports.

Environmental objectives. A clear definition of strategic objectives is required to determine a coherent green strategy in accordance with the overall port strategy, stakeholder interests, external regulations and policies, and social responsibility. As depicted in Fig. 3.1, strategic objectives are considered when applying different means to address environmental issues in a port. Acciaro et al. (2014b) present a list of green strategic objectives linked to the main functions of a port authority.

- Landlord function: This involves the management of port-related areas and activities in a way that negative environmental effects are mitigated. Environmental implications must be considered in portrelated decisions and actions, such as the selection and management of tenants, infrastructure and construction, master planning, dredging, and connectivity (e.g., hinterland transport). Moreover, the relationship between ports and urban environments in terms of sustainable development, especially in port cities, plays a significant role in current discussions (see, e.g., Schulte et al., 2016; Xiao and Lam, 2017; Merk, 2018).

- Regulatory function: This subsumes controlling, auditing, and policy functions to not only ensure safety and security within the port but also environmental protection. The latter involves the regulation of environmental matters as well as implementation, monitoring, and sanctioning in case environmental requirements are not fulfilled.

- Operator function: This traditionally covers the provision of port services with respect to the physical transfer of goods and passengers between sea and land, the provision of technical-nautical services (pilotage, towage, and mooring) and a range of ancillary services. In this regard, the port needs to ensure that the environmental impact is minimized, such as by improving energy efficiency and conservation, as well as when selecting and managing subcontractors.

- Community manager function: A coordinating function for stakeholder management and for maintaining good relationships within the port community. Regarding this role, the port needs to facilitate environmental awareness, stimulate and ensure the adoption of green practices, coordinate environmental activities, and increase the visibility of the green efforts within the port and in public.

Environmental performance indicators. To measure, monitor, and report the performance and trends of environmental activities, resulting from the implementation of a green strategy, environmental performance indicators must be specified. As depicted in Fig. 3.1, measuring and 
reporting those indicators serve as a feedback loop for port governance and management. Recently, Puig et al. (2014) have identified and assessed a comprehensive set of indicators for maritime ports. According to the categories of environmental indicators specified in ISO 14031, the indicators are grouped as follows:

- Management performance indicators (MPIs): A set of indicators devoted to evaluating the efforts made by the port towards the implementation of an environmental management system (EMS) which is used to organize and manage environmental programs in the port. This involves, for example, indicators to assess the implementation of processes for auditing, monitoring, budgeting, training and awareness, communication, and emergency planning.

- Operational performance indicators (OPIs): Allow the assessment of port operations in terms of resource consumption, noise, waste management, and port development.

- Environmental condition indicators (ECIs): These indicators are used to measure and analyze the quality and state of environmental conditions, such as with respect to the quality of air (e.g., regarding GHG emissions like $\mathrm{CO}_{2}, \mathrm{SO}_{x}, \mathrm{NO}$ ), water, soil, and sediments. Indicators to show the status of specific flora and fauna species are also contained in this category.

Policies and regulations. A port policy can be regarded as an essential governance instrument for implementing green objectives and regulating port activities of individual actors (see, e.g., Lam and Notteboom, 2014). As environmental policies and regulations may impose substantial costs, a balance between environmental quality and economic feasibility must be sought. The government is responsible for making public policies and regulations at the local, regional, national, and supranational level, whereas the national authorities are, in some cases, the local enforcement authority of international conventions, such as regarding IMO (International Maritime Organization) conventions (Geerling and Vellinga, 2018). Blinge (2014) groups policy measures for establishing a "green transport corridor" according to related incentives.

- Economic incentives: To promote energy-efficient transport, better utilization of resources, and the use of advanced environmental technologies. Common examples include tax incentives, extended gate hours (e.g., Giuliano and O'Brien, 2007), pricing strategies such as port due discounts for eco-friendly ships (see, e.g., Bergqvist and Egels-Zandén, 2012; Lam and Notteboom, 2014), penalizing and restricting access to ports, and financial incentives for modal shifts.

- Legal incentives: Regulations that hinder unwanted intensive transport activities or reduce/ban polluting technologies in certain 
areas (e.g., low-emission zones, emission control areas), e.g., to improve access for other port actors. Examples include the Clean Truck Program in US ports (e.g., Port of Los Angeles and Long Beach) and the application of specific access rules for trucks in the Maasvlakte II area at the Port of Rotterdam (Netherlands), where only trucks with certain emission standards can enter.

- Supporting incentives: Involves investments and grants for promoting the adoption and development of eco-friendly infrastructure, procedures, and technologies. Examples are truck replacement programs to facilitate the use of clean energy engines. This may also include investments in infrastructure (e.g., equipment for cold ironing, clean bunkering, renewable energy) and information technology. An example is the Maritime Singapore Green Initiative (MSGI), which has provided huge grants within several programs for reducing the environmental impact of port-related activities.

- Voluntary incentives: By participating in voluntary programs, companies may benefit from better public perception and might get free access to technical innovations and best practices. Often, policy-makers use voluntary incentives to test potential policies, which may reduce the transition time for participants in case the policy is implemented.

Management practices. Ports have been early adopters of EMS as a systematic approach to manage and certify port operations (Geerlings and Vellinga, 2018; Lam and Notteboom, 2014). Taking into account welldefined standards and performance indicators, the overall goal is to enhance the environmental performance, fulfillment of compliance obligations, and achievement of environmental objectives (cf. ISO 14001). EcoPorts has developed a basic EMS designed to facilitate environmental certification and specifically adapted to the needs of maritime ports. It is built from elements of the ISO 14001 system, facilitates environmental certification, and can be implemented by applying the port environmental self-diagnosis method (SDM) and implementing the port environmental review system (PERS), allowing the port to apply for a certificate (GreenPorts, 2009). As supporting incentive, the AAPA, for example, has sponsored an EMS program for over 25 port authorities (Geerlings and Vellinga, 2018). An environmental management information system (EMIS) further supports the management in obtaining, processing, and distributing relevant environmental information in response to internal and external requirements (e.g., regulations, policies, stakeholder interests; see El-Gayar and Fritz, 2006). Environmental risk analysis is another responsibility of ports to identify, assess, and prioritize risks associated with environmental duties and liabilities for environmental damage. As seen in Europe, a mutual collaboration between the port sector, research institutes, and specialist organizations, 
fully supported by the ESPO, has paved the way for an improved concept of port environmental management. Moreover, an international working group, in collaboration with the International Association of Ports and Harbours (IAPH) and the World Association for Waterborne Transport Infrastructure (PIANC), is working on guidelines for sustainable reporting (Geerlings and Vellinga, 2018).

Infrastructure and technologies. The improvement of port infrastructure and the use of innovative port technologies can lead to enormous energy savings and reduced emissions. This includes energyefficient vehicle and handling technologies, such as battery-powered automated guided vehicles (AGVs) or electric rubber-tired gantries (Yang and Chang, 2013), as well as the development of an improved transport infrastructure using intelligent transportation systems (ITSs) to mitigate traffic congestion and facilitate intermodal transportation (Geerlings and Vellinga, 2018). Broader concepts, for instance, towards designing green/sustainable ports and terminals (see, e.g., Rijsenbrij and Wieschemann, 2011) and dry ports (Roso, 2007) are also widely discussed. Moreover, the environmental impacts of infrastructure projects, such as regarding dredging activities and techniques (see, e.g., Bray, 2008), need to be considered.

Planning and optimization. Besides adapting port governance and management practices and investing in innovative infrastructure and technologies, an enormous potential for making port operations more eco-efficient lies in the consideration of environmental aspects while planning and optimizing port operations and activities. This not only involves the internal activities of individual port actors, but also the coordination and collaboration among different actors along the logistics chains. For a general overview of planning and optimization in ports and container terminals, the reader is referred to Steenken et al. (2004) and Stahlbock and Vo $\beta$ (2008). Mitigating the environmental impact means explicitly considering ECIs in the planning and optimization phase. To reduce energy consumption and better utilize available resources, several concepts have been introduced in recent years. Regarding landside operations, for example, the implementation of gate/truck appointment systems has been intensively discussed (see, e.g., Zehender and Feillet, 2014). Moreover, slow steaming and the management of vessel arrivals for reducing the fuel consumption of seagoing vessels gain increasing attention in the research community (see Sections 4.2 and 4.3). In a broader context, green logistics has attracted many contributions from the field of operations research (for an overview, the interested reader is referred to Dekker et al., 2012). Decision makers usually cannot only take environmental objectives into account; often, a good trade-off between economic and environmental goals needs to be found, leading to multicriteria decision problems. Recently, gaps in the theoretical development 
and implementation of multiobjective decision support systems in maritime logistics, taking into account environmental sustainability, have been identified (Mansouri et al., 2015). While maritime decision support systems are highly dependent on the integration of various sources of data from different internal and external information systems (for a comprehensive overview of information systems, the reader is referred to Heilig and Vo $\beta, 2017 a$ ), current approaches usually obtain data manually and lack timely and informative decision support. In this regard, Heilig et al. (2017) present a cloud-based multiobjective decision support system for supporting interterminal truck routing by taking into account realtime information (e.g., traffic forecasts) and heavy-duty truck emissions in a multiobjective fashion.

\section{A BRIEF OVERVIEW OF MARITIME LOGISTICS AND PORT OPERATIONS}

Maritime logistics can be defined as the marriage between maritime transport-moving containerized cargo within and between two or more seaports - and principles of logistics and supply chain management (see, e.g., Panayides and Song, 2013). The unification of those different concepts aims for a better integration to address the evolving demands of customers, improving financial and operational performance, increasing quality, and enhancing environmental performance, growth, and corporate responsibility. The concept of integration not only involves physical integration (intermodal) but also economic/strategic (vertical integration, governance structure) or organizational (relational, people, and process integration across organizations) integration. For a detailed introduction, the interested reader is referred to Panayides (2006). In recent years, the emerging discipline has attracted increased attention in academia and practice. Especially the role of ports has drastically changed from its traditional function, connecting sea and landside by facilitating discharging and loading operations, to an essential part in global logistics networks that efficiently and safely manages flows of cargo and offers value-added logistics services. In this regard, one of the main challenges of port logistics is to facilitate the planning, control, coordination, and collaboration among various involved port community members, especially to manage activities at the interfaces in distinct phases of transportation, storage, and other related port logistics activities.

A container terminal is a large infrastructure located in a seaport and aimed at connecting maritime and landside cargo flows by means of container handling, transport, and stacking equipment. It can be seen as an open system of material flow. The main horizontal means of transport typically found at a container terminal are internal vehicles (e.g., AGVs, 
straddle carriers, reach stacker), trucks, inland waterway systems, and trains, whereas the handover of containers is often performed by special cranes (e.g., quay/gantry cranes). The main goal of a container terminal is, hence, to efficiently perform the storage, handover, and transport of containerized freight between those different means of transport. The containers are temporarily stored by the terminal for transshipment or until their final means of transport pick them up and retrieve them from the terminal.

The scheme of a container terminal, as depicted in Fig. 3.2, can be structured around three main functional areas:

Seaside. The area of the container terminal in which container vessels are berthed to be discharged and loaded by a subset of quay cranes. Thus, in this area, the main resources are the berths and quay cranes. Berths are special locations along the quayside to accommodate a vessel. On the other hand, the quay cranes (i.e., ship-to-shore gantry cranes) are the specialized machinery aimed at performing loading and unloading at a berth.

Yard. The area dedicated to the temporary storage of containers. It is divided into blocks, where each block is organized into bays, rows, and tiers. The incoming containers are stacked upon each other by the yard machinery (e.g., rubber-tired gantry cranes, rail-mounted gantry cranes, reach stackers) until their later retrieval for continuing their route through the seaside, by means of container or feeder vessels, through the landside by means of trucks or trains, or through inland waterways (e.g., using barges). Moreover, dedicated areas for specific types of containers (e.g., reefer, empty), maintenance and repair stations, and packing stations could be located at the terminal site or in another area of the seaport.

Landside. This area links the maritime container terminal with land transportation modes, which is usually divided into a truck and rail area. Terminal gates handle landside inbound and outbound cargo flows. The gate procedures involve checking the container documentation, inspection of damages and cargo hazard classifications, as well as the permissions of trucks to access/exit the terminal with certain containers. Gate appointment systems are commonly implemented to better plan and schedule the arrival and departure of trucks from/to the hinterland.

Taking into account these different areas, several logistics planning activities must be considered to ensure a smooth flow of cargo and information. According to, e.g., Steenken et al. (2004), this involves especially the following tasks:

Berthing. Each incoming container vessel has to be assigned to a position along the quay according to its particular characteristics (e.g., dimensions, stowage plan, contractual agreements) as well as the terminal characteristics (e.g., berths water depth, working time-windows, etc.). The main logistics problem arising at this stage is the berth allocation problem 
Seaside

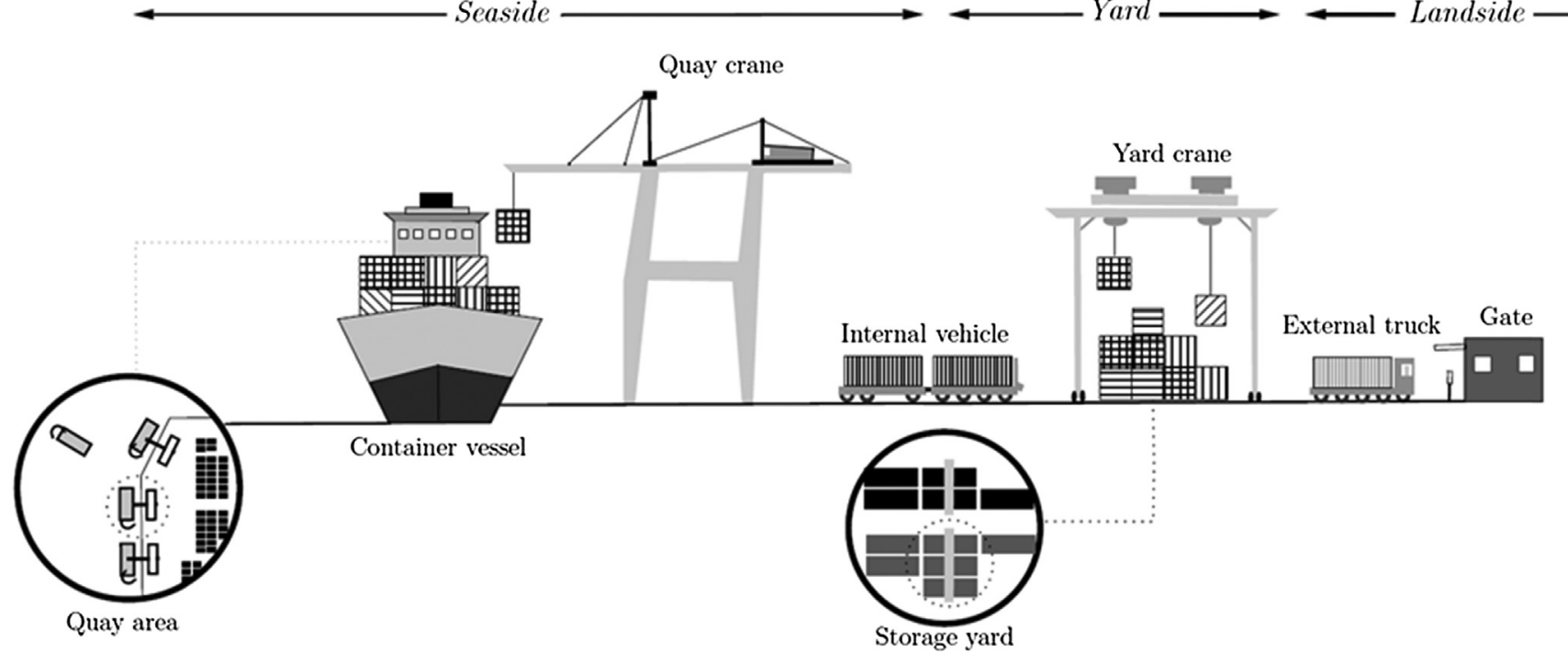

FIGURE 3.2 Schematic overview of a maritime container terminal (Lalla-Ruiz, 2017). 
(BAP). From an environmental viewpoint, knowing in advance the different time windows of the vessels for visiting the ports enables the option of managing their traveling speed when arriving and departing to/from a container terminal as well as along the different paths in their route. This way, emissions can be reduced meaningfully without losing competitiveness (see Section 4). The implementation of such environmental strategies requires properly considering the different vessel types and loads, the vessel-port time-windows as well as the paths considered in their given route or the geographical situation of the port, among others. Cooper (2003) and Adamo et al. (2014) present approaches to determine the emissions of vessels while staying at the berth. The latter work further takes into account cold-ironing (i.e., shore-power) as an alternative power source. A cost model to assess the environmental impact of routine shipping operations in ports using simulations is presented in $\mathrm{Ng}$ and Song (2010).

Quay crane deployment. Once the container vessel is allocated at the quay of a given container terminal, a subset of quay cranes has to be assigned and scheduled to the vessel in order to perform its associated operations. The quay crane allocation problem (QCAP) and quay crane scheduling problem (QCSP) are the most relevant problems in this respect. In this regard, some works investigate quay crane deployment problems taking into consideration the arrival of vessels in terms of fuel consumption and tidal impact (see, e.g., Yu et al., 2017; Du et al., 2011). On the other hand, improving the synchronization (i.e., handshake) between seaside and yard operations contributes to a better trade-off between efficiency (e.g., in terms of time-saving) and energy consumption. In this context, He et al. (2015) address the problem of integrated quay crane scheduling, internal truck scheduling, and yard crane scheduling.

Yard management. This comprises the management and storage of containers until their release for continuing their routes within vessels, trucks, or trains. Container storage and yard crane scheduling problems arise in this operational area such as the block(s) relocation problem, the remarshaling problem, the premarshaling problem, and the yard crane scheduling problem (see, e.g., Caserta et al., 2011). The management of the yard has a relevant impact in emission reduction as it allows reducing the number of yard crane movements, which have a direct impact on the yard crane fuel consumption, while also decreasing traffic congestion concerning the vehicles involved in the movement of containers. On the other hand, the consideration of electric handling equipment and its adapted management alleviates noise while reducing pollution (Yang and Chang, 2013). Rijsenbrij and Wieschemann (2011) present a sustainable design for stacking operations in container terminals. 
Transport and delivery of containers. This is composed of the movement of containers from the quay to the storage area and from the storage area to the hinterland, and vice versa. In some cases, a direct movement between quay and hinterland is allowed. Moreover, aspects of gate/terminal appointment systems and interterminal transportation (ITT) have been increasingly discussed in recent years (Heilig and Vo $\beta, 2017 a, b)$. In this context, some of the main optimization problems are the vehicle dispatching problem (VDP), pickup and delivery problems, and the gate operations planning problem (GOPP). Regarding the environmental impact of vehicle routing, the interested reader is referred to literature overviews on green logistics and green vehicle routing presented, e.g., in Dekker et al. (2012) and Sbihi and Eglese (2007). In seaports, as discussed in Section 2, the use of innovative transport technologies, such as batterypowered AGVs and trucks, can lead to enormous energy savings and reduced emissions. Several approaches have been presented in the literature to deal with environmental factors of transport in seaports. Islam et al. (2013) and Schulte et al. (2017) investigate truck-sharing arrangements using truck appointment systems to reduce empty-truck trips, causing a considerable amount of avoidable emissions. Lättilä et al. (2013) and Palacio et al. (2016) consider the effect of dry ports and container depots on emissions.

Considering the rich literature as well as the diverse possibilities for leading container terminals to be environmentally sustainable, in the following we deepen and illustrate how the sustainability dimension can be taken into account within berth scheduling operations.

\section{AN APPLICATION TO BERTH SCHEDULING}

From a planning and optimization perspective, environmentally sustainable port operations require proper models and approaches considering and analyzing the environmental impact of those decisions taken through different metrics (see Section 2, "Planning and Optimization"). Thus, this section aims at introducing, by means of an exemplary problem in port operations, how the different environmental sustainability concepts can be applied to operational decision making. In doing so, first, the berthing operations considered in the well-known BAP are addressed from a green perspective. Later, the different strategies and solution approaches involving the optimization of environmental indicators are described.

\subsection{Description of the Problem}

The BAP is an optimization problem arising at the seaside of maritime terminals aiming to schedule vessels arriving at the port within a given planning horizon. Generally, the main constraints involved in this 
problem are those related to berthing positions (e.g., to avoid space overlapping in the same time) and for ensuring that vessels are berthed during, at least, their whole service time. The traditional objective in the $\mathrm{BAP}$ is to serve all vessels in such a way that their turnaround times are as short as possible while satisfying the berthing constraints.

Different variants of the BAP can be found in the literature (Bierthwirth and Meisel, 2015). According to their arrival time, the problem can be considered as static or dynamic. In the static case, all vessels are already in the port before the planning starts. On the other hand, the dynamic case considers vessels arriving along the time horizon. Furthermore, the BAP has variants according to the berth layout of the terminal. That is, depending on the consideration of the berth, the BAP can be considered as continuous, discrete, or hybrid. While in the continuous case the quay is not divided, in the discrete it is divided into segments referred to as berths. It should be noted in this case that a berth can serve a certain number of vessels at each time step. The hybrid consideration also partitions the quay into berths but allows vessels to share berths according to their length.

\subsection{Including Environmental Sustainability in Berthing Operations}

One of the most important ECIs (see Section 2) is the reduction of GHG emissions. With regards to berthing operations, this mainly relates to the vessel speed when sailing to the next port of call and approaching a terminal as well as the time the vessel stays at the port. In this regard, industry reports and works in the specialized literature (Shi et al., 2013; Gibbs et al., 2014; Cullinane et al., 2016) indicate that, although a relevant amount of emissions occurs due to the sailing period, a significant amount is also generated during the mooring period of the vessel.

The relationship between fuel consumption and induced emissions is one of the main considered features in maritime transport with regards to the reduction of GHG emissions. In this context, slow steaming arises as an operational practice consisting of deliberately reducing the speed of vessels in order to cut down the fuel consumption and emissions. This practice also has a beneficial impact in cost savings and reducing the excess of fleet capacity (Meyer et al., 2012; Maloni et al., 2013; Kontovas and Psaraftis, 2013); the latter especially during periods of slack demand. Meyer et al. (2012) investigate the economic aspect of this strategy from different sides indicating that the optimal vessel speed depends on freight rates and fuel prices. Thus, when applying this operational strategy, and depending on the speed reduction and economic context, different degrees of slow steaming can be considered. That is, slow steaming, extra 
slow steaming, and super slow steaming. Table 3.1 reports an indicative summary of the abovementioned speed strategies (see also Maloni et al., 2013). The benefits of slow steaming are not only environmental but also economic as it allows reducing the fuel costs and balancing the relationship between supply and demand depending on the carrier capacity.

Figs. 3.3 and 3.4 report the annual costs and emissions (in metric tonnes, MT) as a function of the vessel speed, respectively. The plots depict the trade-off between the annual ocean carrier and shipper costs (in USD) and $\mathrm{CO}_{2}$ emissions at different vessel speeds. Although in terms of emissions super slow steaming provides the best reductions, as can be seen in the figures, extra slow steaming is the one providing the best trade-off with respect to annual costs. The increase of annual costs finds its rationale in costs. Thus, depending on the freight rates and fuel prices, the level of slow steaming should be considered, especially when fuel costs are high and freight rates are from medium to low. In those cases, it is profitable to reduce speed and apply this type of speed strategies.

Fig. 3.5 shows the cost per million tonnes per nautical mile $(\mathrm{nm})$ in USD as a function of vessel speed and emissions considering (1) the fuel costs, (2) the time charter (TC), and (3) the capital cost of transported goods. Moreover, in the case of emissions, the lifecycle emissions associated with the increased number of vessels (i.e., shipbuilding), ensuring a constant flow of goods when reducing speed, is shown. The cost of cargo is gradually reduced from super slow steaming to extra slow steaming, as indicated by the pointed line. On the other hand, the reduction of emissions when applying the low steaming strategy can be observed.

The fuel reduction of slow steaming is mainly regarded as the result of the reduction of used engine power and lower wave and wind

TABLE 3.1 Types of Speed Reduction Strategies

\begin{tabular}{l|l|l|l}
\hline Type & $\begin{array}{l}\text { Speed Range } \\
\text { (Knots) }\end{array}$ & $\begin{array}{l}\text { Speed } \\
\text { reduction }{ }^{\text {(\%) }}\end{array}$ & Description \\
\hline $\begin{array}{l}\text { Normal speed } \\
\text { Slow steaming }\end{array}$ & $20-25$ & 0 & $\begin{array}{l}\text { Optimal cruising speed } \\
\text { Engines working below } \\
\text { capacity to save fuel } \\
\text { consumption } \\
\text { Minimal fuel consumption } \\
\text { while maintaining a } \\
\text { commercial service } \\
\text { Lxtra slow } \\
\text { steaming }\end{array}$ \\
$15-18$ & $20-25$ & $\begin{array}{l}\text { Lowest technically } \\
\text { possible speed }\end{array}$ \\
$\begin{array}{l}\text { Super slow } \\
\text { steaming }\end{array}$ & $<15$ & $>25$ & \multicolumn{2}{l}{} \\
\hline
\end{tabular}

${ }^{a}$ With regards to their designed engine speed. 


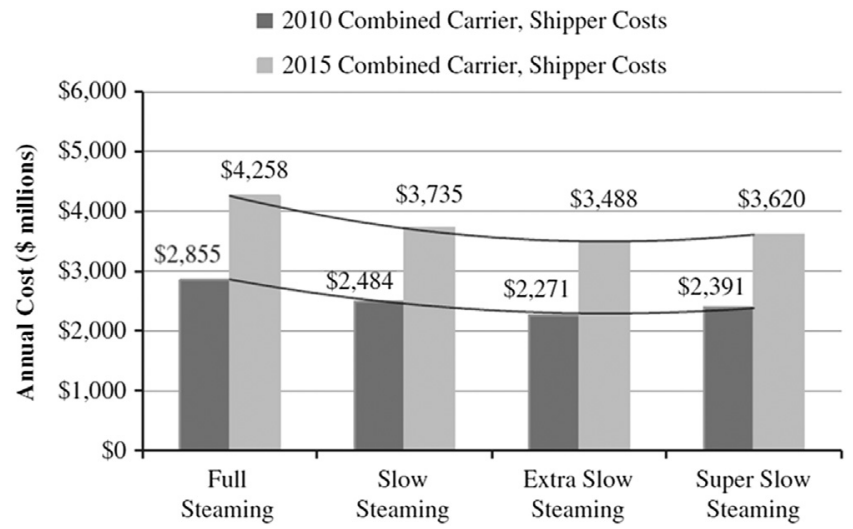

FIGURE 3.3 Ocean and carrier annual costs per each steaming strategy (Maloni et al., 2013).

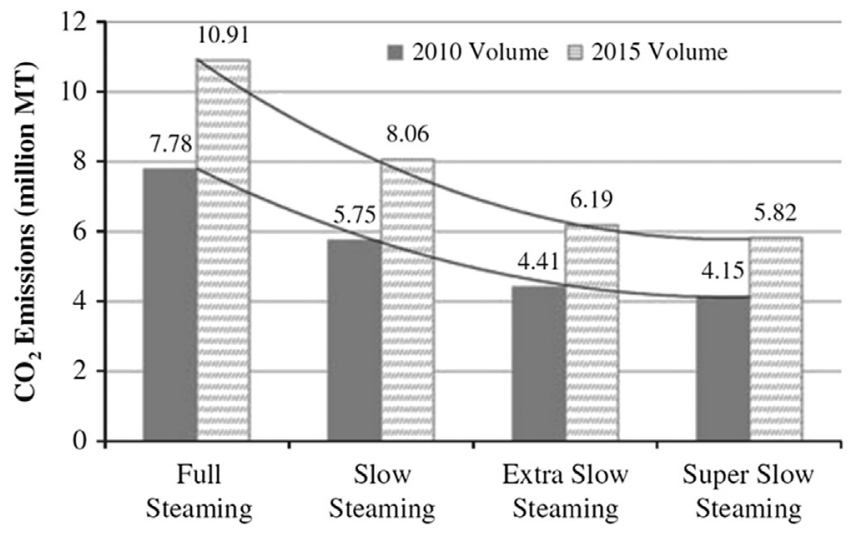

FIGURE 3.4 Ocean and carrier emissions per each steaming strategy (Maloni et al., 2013).

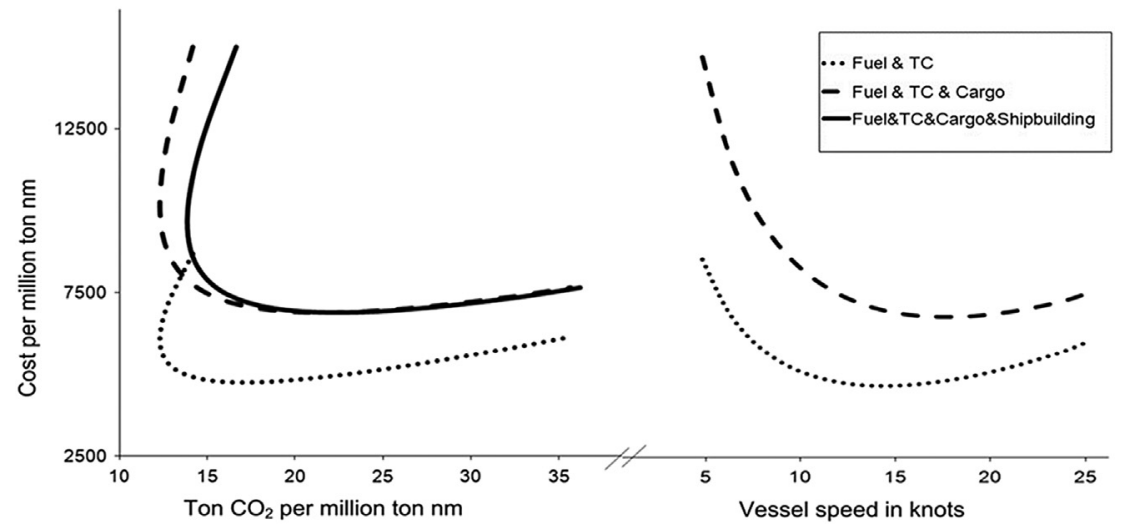

FIGURE 3.5 Emissions and costs as a function of vessel speed (Lindstad et al., 2011). 
resistance. In the related literature, fuel consumption is usually represented by the cubic formula:

$$
F(s)=\left(\frac{v}{v_{d}}\right)^{3} \cdot f_{d}
$$

where $v$ is the traveling speed measured in knots, $v_{d}$ is the design speed of the vessel, and $f_{d}$ is the fuel consumption in tonnes/hour at the designed speed. It should be noted that the resulting value of $F(s)$ is the fuel consumption measured in tonnes/hour. However, this formula is not appropriate as a basis for reliable calculations of fuel consumption under real-world conditions (Meyer et al., 2012). As previously mentioned, wave and wind resistance have an impact on fuel consumption. Lindstand et al. (2011) propose an updated formula for calculating the fuel consumption of a vessel that, besides calculating fuel consumption as a function of the speed, explicitly takes into consideration the propeller efficiency, the time in port and slow zones for the considered roundtrip, the power needed $(P)$ which considers still water conditions, and the additional power for waves and auxiliary engines:

$$
F=F_{s}+F_{p \& s}=K_{f}\left(\left(\frac{P \cdot D}{v}\right)+\left(P_{p \& s} \cdot T_{p \& s}\right)\right)
$$

where $F_{s}$ represents the fuel consumption during sailing and $F_{p \& s}$ the fuel consumption in slow zones and in port. Moreover, this formula is composed of $K_{f}$ as the amount of fuel used per work unit produced by the propeller, $P$ as the total power required, $D$ as the roundtrip distance, and $P_{p \& s}$ and $T_{p \& s}$ as the power requirement and time used in port and slow zones, respectively.

As discussed in Du et al. (2011), the absence of methodologies and monitoring programs for precise measurement of vessel emissions leads to the calculation of them as a multiplication between fuel consumption and emission factors $\left(e_{f}\right)$ :

$$
E=F \cdot e_{f}
$$

However, the energy efficiency operational indicator (EEOI), which is introduced in Marine Environment Protection Committee (2009), allows evaluating energy efficiency and $\mathrm{CO}_{2}$ gas emission and would be a valid and more detailed option.

$$
E E I O=\frac{F}{D \cdot M} \cdot C_{e}
$$

where $M$ corresponds to the weight of the ship in tonnes and $C_{e}$ is the fuel mass conversion to $\mathrm{CO}_{2}$. Based on this formula, the unit of EEIO is tonnes of $\mathrm{CO}_{2}$ per nautical mile. Through formulas (3.2) and (3.4), the fuel and 
emissions of the vessels arriving at a port can be estimated. It should be noted that the combination of Eqs. (3.2) and (3.4) would be the most accurate choice for assessing emissions.

To contextualize the slow steaming approach, an example can be found in Wackett (2013). For a containership carrying 10,000 TEU at a slow steaming speed of 18-20 knots instead of its optimal designed cruising speed of 20-25 knots, daily savings of 175 tonnes of bunker can be achieved. Moreover, at extra slow steaming (15-18 knots), the consumption is improved even further, saving an additional 100 tonnes per day. In 2009, more than $90 \%$ of vessel operators, participating in the Clean Air Action Program (CAAP), voluntarily reduced speed in return for reduced port fees of 15\% (Gibbs et al., 2014). Nevertheless, a trade-off between the costs and the scheduled agreements has to be met in those cases where there is no sufficient idle capacity in the route, provoking extended vessel voyage times. As a consequence, this may lead to a loss of competitiveness.

\subsection{Improving Sustainability in the Berth Allocation Problem}

As noted above, to appropriately consider and tackle sustainability in berthing operations, the decision support and planning systems have to adopt strategies and approaches comprising vessel speed reductions and enhancing the management of the involved resources.

Table 3.2 summarizes the different decision support approaches devoted to solving the BAP and optimizing the impact emissions in this problem. This table differentiates between (1) the goals with respect to the objective to be optimized, (2) if the different goals are bundled in one unique objective or in a multiobjective setting, and (3) the type of BAP considered, and the decision support approach proposed. Regarding the type, the considered works differentiate, in terms of the spatial attribute, between discrete (disc) and continuous (cont) berths. The problem has been modeled as a dynamic problem $(d y n)$ with respect to the temporal characteristics.

The objective regarding time usually aims at reducing the waiting and service time of vessels. Although the measuring unit of the function for optimizing is in the temporal range, it has a direct impact on air emissions (Gibbs et al., 2014; Lalla-Ruiz et al., 2018; Cullinane et al., 2016). To appropriately translate the time goal into emissions, the following formula can be considered:

$$
E_{\text {berth }}=P \cdot L F \cdot A \cdot e_{f}
$$

where $E_{\text {berth }}$ corresponds to the emissions in grams produced at the berth considering a maximum continuous rating power $P$ measured in kilowatts, a load factor $L F$ corresponding to the percentage of the vessel's power, the activity $A$ (in hours), and the emission factor $e_{f}$. 
TABLE 3.2 Decision support approaches for the BAP considering sustainability

\begin{tabular}{|c|c|c|c|c|c|c|c|}
\hline \multirow[b]{2}{*}{ Type } & \multicolumn{4}{|c|}{ Goal } & \multirow[b]{2}{*}{ Multiobjective } & \multirow[b]{2}{*}{ Type of BAP } & \multirow[b]{2}{*}{ Solution Approach } \\
\hline & Time & Costs & Fuel & Emissions & & & \\
\hline Golias et al. (2010) & - & & - & - & O & disc, dyn & Genetic algorithm \\
\hline Alvarez et al. (2010) & $\bullet$ & $\bullet$ & & - & O & disc, dyn & Simulation \\
\hline Lang and Veenstra (2010) & & $\bullet$ & $\bullet$ & & ○ & cont, dyn & $\begin{array}{l}\text { Mixed-integer linear } \\
\text { programming }\end{array}$ \\
\hline Du et al. (2011) & ○ & & $\bullet$ & & $\bullet$ & cont, dyn & MISOCP $^{a}, \varepsilon$-constraint \\
\hline Wang et al. (2013) & $\bullet$ & $\bullet$ & & & $\bullet$ & cont, dyn & $\mathrm{QOA}^{\mathrm{b}}$ \\
\hline
\end{tabular}


Although in some approaches the time is not explicitly used, its transformation into costs is included in such objectives. Similarly, the transformation from fuel to emissions by means of Eq. (3.3) can also be used when the approach is only reducing fuel consumption.

As discussed in Heilig et al. (2017), diverse ways of tackling multiple objectives may be applied, which depend on the requirements of the planner. Generally, when a single objective is considered, a combination of the objectives by means of weights is used. On the other hand, when multiple objectives are considered in a multiobjective fashion, all the trade-off solutions among the different objectives can be obtained. It should be noted that in the work of Du et al. (2011) an $\varepsilon$-constraint method is proposed. This method consists of optimizing one objective while the other criteria are used as restrictions.

In the works listed in Table 3.2, the sustainability dimension of the BAP is generally addressed by considering the speed control of the vessel, the arrival of the vessel, and the use of berths. Du et al. (2015) investigate the virtual arrival policy together with berthing operations. This strategy consists of managing vessels' speed in order to meet their berthing time windows. In that work, the virtual arrival is considered as a decision variable which is primarily used to mitigate the impacts of tides. As a result, the virtual arrival policy arises as an important policy to reduce fuel consumption and related emissions. Venturini et al. (2017) tackle the multiport berth allocation problem considering slow steaming by means of different sailing speeds associated with each vessel. This way, they optimize the speed for each vessel at each leg within a predetermined route. Through this approach, a $42 \%$ reduction of emissions in the entire network was obtained when compared to the use of conventional vessel design speed.

\section{CONCLUSIONS}

Environmental sustainability describes a broad concept for supporting eco-friendly production and efficient use of resources in order to mitigate and avoid a negative impact on future generations. For integrating this concept into practice, it is important to put it into perspective with regards to maritime ports. In this chapter, we first identified core areas of environmental sustainability and presented a framework that classifies and explains different types of approaches for addressing environmental issues in maritime ports on various operational levels. Focusing on planning and optimization tasks in container terminals, we explained and discussed the impact of slow steaming and vessel arrival times on berthing operations. As a result, we show how decision support can be designed in a way to explicitly consider concepts and strategies of environmental sustainability. 
In addition, it is important to incorporate the wide opportunities offered by emerging trends of digitalization (e.g., internet of things, intelligent transportation systems) for dealing with open issues regarding the environmental sustainability of maritime ports. While only a few studies of environmental sustainability incorporate an information systems perspective, it can play a critical role in shaping organizational practices and processes improving both economic and environmental performance (Melville, 2010; Heilig et al., 2017). As a consequence, interdisciplinary research, e.g., addressing planning and optimization problems, is needed. For future research, we intend to focus on an integrated view of berth planning and optimization with respect to related terminal and hinterland operations. In this respect, we aim to not only consider the environmental factors in those operations, but also the impact of operational disturbances.

\section{References}

AAPA, 1998. Environmental Management Handbook. American Association of Port Authorities (AAPA). http:/ / www.aapa-ports.org/empowering/content.aspx?ItemNumber=989.

Acciaro, M., Ghiara, H., Cusano, M.I., 2014a. Energy management in seaports: a new role for port authorities. Energy Policy 71, 4-12.

Acciaro, M., Vanelslander, T., Sys, C., Ferrari, C., Roumboutsos, A., Giuliano, G., Lam, J.S.L., Kapros, S., 2014b. Environmental sustainability in seaports: a framework for successful innovation. Maritime Policy \& Management 41 (5), 480-500.

Adamo, F., Andria, G., Cavone, G., De Capua, C., Lanzolla, A.M.L., Morello, R., Spadavecchia, M., 2014. Estimation of ship emissions in the port of Taranto. Measurement $47,982-988$.

Alvarez, J.F., Longva, T., Engebrethsen, E.S., 2010. A methodology to assess vessel berthing and speed optimization policies. Maritime Economics \& Logistics 12 (4), 327-346.

Antão, P., Calderón, M., Puig, M., Michail, A., Wooldridge, C., Darbra, R.M., 2016. Identification of occupational health, safety, security (OHSS) and environmental performance indicators in port areas. Safety Science 85, 266-275.

Bergqvist, R., Egels-Zandén, N., 2012. Green port dues: the case of hinterland transport. Research in Transportation Business \& Management 5, 85-91.

Bierwirth, C., Meisel, F., 2015. A follow-up survey of berth allocation and quay crane scheduling problems in container terminals. European Journal of Operational Research 244 (3), 675-689.

Blinge, M., 2014. Policy measures to realise green corridors: a stakeholder perspective. Research in Transportation Business \& Management 12, 55-62.

Bray, R.N., 2008. Environmental Aspects of Dredging. CRC Press.

Brundtland, G.H., 1987. Our common future: call for action. Environmental Conservation 14 (4), 291-294.

Caserta, M., Schwarze, S., Voß, S., 2011. Container rehandling at maritime container terminals. In: Böse, J.W. (Ed.), Handbook of Terminal Planning. Springer, New York, pp. 247-269.

Cooper, D.A., 2003. Exhaust emissions from ships at berth. Atmospheric Environment 37 (27), 3817-3830.

Cullinane, K., Tseng, P.H., Wilmsmeier, G., 2016. Estimation of container ship emissions at berth in Taiwan. International Journal of Sustainable Transportation 10 (5), 466-474. 
Davarzani, H., Fahimnia, B., Bell, M., Sarkis, J., 2016. Greening ports and maritime logistics: a review. Transportation Research Part D: Transport and Environment 48, 473-487.

Dekker, R., Bloemhof, J., Mallidis, I., 2012. Operations research for green logistics: an overview of aspects, issues, contributions and challenges. European Journal of Operational Research 219 (3), 671-679.

Denktas-Sakar, G., Karatas-Cetin, C., 2012. Port sustainability and stakeholder management in supply chains: a framework on resource dependence theory. The Asian Journal of Shipping and Logistics 28 (3), 301-319.

Dooms, M., Haezendonck, E., Valaert, T., 2013. Dynamic green portfolio analysis for inland ports: an empirical analysis on Western Europe. Research in Transportation Business \& Management 8, 171-185.

Du, Y., Chen, Q., Quan, X., Long, L., Fung, R.Y., 2011. Berth allocation considering fuel consumption and vessel emissions. Transportation Research Part E: Logistics and Transportation Review 47 (6), 1021-1037.

Du, Y., Chen, Q., Lam, J.S.L., Xu, Y., Cao, J.X., 2015. Modeling the impacts of tides and the virtual arrival policy in berth allocation. Transportation Science 49 (4), 939-956.

El-Gayar, O., Fritz, B.D., 2006. Environmental management information systems (EMIS) for sustainable development: a conceptual overview. Communications of the Association for Information Systems 17 (1), 756-784.

ESPO, 2012. Towards Excellence in Port Environmental Management and Sustainability. European Sea Ports Organisation (ESPO). https://www.espo.be/publications/espo-greenguide-towards-excellence-in-port-enviro.

ESPO, 2016. Port Environmental Review 2016-Insight on Port Environmental Performance and its Evolution over Time. European Sea Ports Organisation (ESPO). https://www. espo.be/media/news/ESPO_EcoPorts\%20Port\%20Environmental\%20Review\% 202016.pdf.

Geerlings, H., Vellinga, T., 2018. Sustainability. In: Geerlings, H., Kuipers, B., Zuidwijk, R. (Eds.), Ports and Networks. Routledge, London, pp. 296-314.

Gibbs, D., Rigot-Muller, P., Mangan, J., Lalwani, C., 2014. The role of sea ports in end-to-end maritime transport chain emissions. Energy Policy 64, 337-348.

Giuliano, G., O'Brien, T., 2007. Reducing port-related truck emissions: the terminal gate appointment system at the ports of Los Angeles and Long Beach. Transportation Research Part D: Transport and Environment 12 (7), 460-473.

Golias, M., Boile, M., Theofanis, S., Efstathiou, C., 2010. The berth-scheduling problem: maximizing berth productivity and minimizing fuel consumption and emissions production. Transportation Research Record: Journal of the Transportation Research Board 2166, $20-27$.

GreenPorts, 2009. Increasing Efficiency in Seaport Environmental Management. http:// www.greenport.com/news101/Projects-and-Initiatives/increasing-efficiency-inseaport-environmental-management.

He, J., Huang, Y., Yan, W., Wang, S., 2015. Integrated internal truck, yard crane and quay crane scheduling in a container terminal considering energy consumption. Expert Systems with Applications 42 (5), 2464-2487.

Heilig, L., Lalla-Ruiz, E., Voß, S., 2017. Multi-objective inter-terminal truck routing. Transportation Research Part E: Logistics and Transportation Review 106, 178-202.

Heilig, L., Voß, S., 2017a. Information systems in seaports: a categorization and overview. Information Technology and Management 18 (3), 179-201.

Heilig, L., Voß, S., 2017b. Inter-terminal transportation: an annotated bibliography and research agenda. Flexible Services and Manufacturing Journal 29 (1), 35-63.

Islam, S., Olsen, T., Daud Ahmed, M., 2013. Reengineering the seaport container truck hauling process: reducing empty slot trips for transport capacity improvement. Business Process Management Journal 19 (5), 752-782. 
Kontovas, C.A., Psaraftis, H., 2013. Speed models for energy-efficient maritime transportation: a taxonomy and survey. Transportation Research Part C: Emerging Technologies $26,331-351$.

Lalla-Ruiz, E., 2017. Intelligent management of seaside logistic operations at maritime container terminals. 4OR 15 (2), 217-218.

Lalla-Ruiz, E., Shi, X., Voß, S., 2018. The waterway ship scheduling problem. Transportation Research Part D: Transport and Environment 60, 191-209.

Lam, J.S.L., Notteboom, T., 2014. The greening of ports: a comparison of port management tools used by leading ports in Asia and Europe. Transport Reviews 34 (2), 169-189.

Lam, J.S.L., Van de Voorde, E., 2012. Green port strategy for sustainable growth and development. In: Transport Logistics for Sustainable Growth at a New Level, International Forum on Shipping, Ports and Airports (IFSPA), Hong Kong, China, pp. 27-30.

Lang, N., Veenstra, A., 2010. A quantitative analysis of container vessel arrival planning strategies. Spectrum 32 (3), 477-499.

Lättilä, L., Henttu, V., Hilmola, O.P., 2013. Hinterland operations of sea ports do matter: dry port usage effects on transportation costs and $\mathrm{CO}_{2}$ emissions. Transportation Research Part E: Logistics and Transportation Review 55, 23-42.

Lindstad, H., Asbjørnslett, B.E., Strømman, A.H., 2011. Reductions in greenhouse gas emissions and cost by shipping at lower speeds. Energy Policy 39 (6), 3456-3464.

Lirn, T.C., Jim Wu, Y.C., Chen, Y.J., 2013. Green performance criteria for sustainable ports in Asia. International Journal of Physical Distribution \& Logistics Management 43 (5/6), 427-451.

Lun, Y.V., 2011. Green management practices and firm performance: a case of container terminal operations. Resources, Conservation and Recycling 55 (6), 559-566.

Mansouri, S.A., Lee, H., Aluko, O., 2015. Multi-objective decision support to enhance environmental sustainability in maritime shipping: a review and future directions. Transportation Research Part E: Logistics and Transportation Review 78, 3-18.

Maloni, M., Paul, J.A., Gligor, D.M., 2013. Slow steaming impacts on ocean carriers and shippers. Maritime Economics \& Logistics 15 (2), 151-171.

Marine Environment Protection Committee, 2009. Guidelines for Voluntary Use of the Ship Energy Efficiency Operational Indicator (EEOI). International Maritime Organization, Report.

Melville, N.P., 2010. Information systems innovation for environmental sustainability. MIS quarterly 34.1,1-21.

Merk, O., 2018. The port-city interface. In: Geerlings, H., Kuipers, B., Zuidwijk, R. (Eds.), Ports and Networks. Routledge, London, pp. 296-314.

Meyer, J., Stahlbock, R., Voß, S., 2012. Slow steaming in container shipping. In: Sprague, R.H. (Ed.), Proceedings of the 45th Hawaii International Conference on System Science. IEEE, Piscataway, pp. 1306-1314.

Mihyeon Jeon, C., Amekudzi, A., 2005. Addressing sustainability in transportation systems: definitions, indicators, and metrics. Journal of Infrastructure Systems 11 (1), 31-50.

$\mathrm{Ng}$, A.K., Song, S., 2010. The environmental impacts of pollutants generated by routine shipping operations on ports. Ocean \& Coastal Management 53 (5), 301-311.

Palacio, A., Adenso-Díaz, B., Lozano, S., Furió, S., 2016. Bicriteria optimization model for locating maritime container depots: application to the port of Valencia. Networks and Spatial Economics 16 (1), 331-348.

Panayides, P.M., 2006. Maritime logistics and global supply chains: towards a research agenda. Maritime Economics \& Logistics 8 (1), 3-18.

Panayides, P.M., Song, D.W., 2013. Maritime logistics as an emerging discipline. Maritime Policy \& Management 40 (3), 295-308.

Peris-Mora, E., Orejas, J.D., Subirats, A., Ibáñez, S., Alvarez, P., 2005. Development of a system of indicators for sustainable port management. Marine Pollution Bulletin 50 (12), $1649-1660$. 
Puig, M., Wooldridge, C., Darbra, R.M., 2014. Identification and selection of environmental performance indicators for sustainable port development. Marine Pollution Bulletin 81 (1), 124-130.

Rijsenbrij, J.C., Wieschemann, A., 2011. Sustainable container terminals: a design approach. In: Böse, J.W. (Ed.), Handbook of Terminal Planning. Springer, New York, pp. 61-82.

Roso, V., 2007. Evaluation of the dry port concept from an environmental perspective: a note. Transportation Research Part D: Transport and Environment 12 (7), 523-527.

Stahlbock, R., Vo $\beta$, S., 2008. Operations research at container terminals - A literature update. OR Spectrum 30, 1-52.

Sbihi, A., Eglese, R.W., 2007. Combinatorial optimization and green logistics. 4OR 5 (2), 99-116.

Schulte, F., Gonzalez-Ramirez, R.G., Ascencio, L.M., Voß, S., 2016. Directions for sustainable ports in Latin America and the Caribbean. International Journal of Transport Economics 43, 315-337.

Schulte, F., Lalla-Ruiz, E., Gonzalez-Ramirez, R.G., Voß, S., 2017. Reducing port-related empty truck emissions: a mathematical approach for truck appointments with collaboration. Transportation Research Part E: Logistics and Transportation Review 105, 195-212.

Shi, X., Zhang, Y., Voß, S., 2013. Actions applied by Chinese shipping companies under greenhouse gas emissions trading scheme. International Journal of Shipping and Transport Logistics 5, 463-484.

Sislian, L., Jaegler, A., Cariou, P., 2016. A literature review on port sustainability and ocean's carrier network problem. Research in Transportation Business \& Management 19, 19-26.

Steenken, D., Voß, S., Stahlbock, R., 2004. Container terminal operation and operations research: a classification and literature review. OR Spectrum 26 (1), 3-49.

UNCTAD, 2016. Review of Maritime Transport. United Nations Conference on Trade and Development. http://unctad.org/en/Pages/Publications/Review-of-MaritimeTransport-(Series).aspx.

Venturini, G., Iris, Ç., Kontovas, C.A., Larsen, A., 2017. The multi-port berth allocation problem with speed optimization and emission considerations. Transportation Research Part D: Transport and Environment 54, 142-159.

Wackett, M., 2013. Lower speeds boost box schedule reliability, say top European customers. Lloyd's List. https://1loydslist.maritimeintelligence.informa.com/LL038265/Lowerspeeds-boost-box-schedule-reliability-say-top-shippers.

Wang, S., Meng, Q., Liu, Z., 2013. A note on "Berth allocation considering fuel consumption and vessel emissions". Transportation Research Part E: Logistics and Transportation Review 49 (1), 48-54.

Xiao, Z., Lam, J.S.L., 2017. A systems framework for the sustainable development of a port city: a case study of Singapore's policies. Research in Transportation Business \& Management 22, 255-262.

Yang, C.S., Lu, C.S., Haider, J.J., Marlow, P.B., 2013. The effect of green supply chain management on green performance and firm competitiveness in the context of container shipping in Taiwan. Transportation Research Part E: Logistics and Transportation Review 55, 55-73.

Yang, Y.C., Chang, W.M., 2013. Impacts of electric rubber-tired gantries on green port performance. Research in Transportation Business \& Management 8, 67-76.

Yu, S., Wang, S., Zhen, L., 2017. Quay crane scheduling problem with considering tidal impact and fuel consumption. Flexible Services and Manufacturing Journal 29 (3-4), 345-368.

Zehendner, E., Feillet, D., 2014. Benefits of a truck appointment system on the service quality of inland transport modes at a multimodal container terminal. European Journal of Operational Research 235 (2), 461-469. 